\title{
A Lagrangian analysis of upper-tropospheric anticyclones associated with heat waves in Europe
}

\author{
Philipp Zschenderlein ${ }^{1}$, Stephan Pfahl ${ }^{2}$, Heini Wernli ${ }^{3}$, and Andreas H. Fink ${ }^{1}$ \\ ${ }^{1}$ Institute of Meteorology and Climate Research, Karlsruhe Institute of Technology, \\ Wolfgang-Gaede-Str. 1, 76131 Karlsruhe, Germany \\ ${ }^{2}$ Institute of Meteorology, Freie Universität Berlin, Carl-Heinrich-Becker Weg 6-10, 12165 Berlin, Germany \\ ${ }^{3}$ Institute for Atmospheric and Climate Science, ETH Zurich, Universitätstr. 16, 8092 Zurich, Switzerland
}

Correspondence: Philipp Zschenderlein (philipp.zschenderlein@kit.edu)

Received: 16 December 2019 - Discussion started: 10 January 2020

Revised: 9 April 2020 - Accepted: 17 April 2020 - Published: 28 April 2020

\begin{abstract}
This study presents a Lagrangian analysis of upper-tropospheric anticyclones that are connected to surface heat waves in different European regions for the period 1979 to 2016. In order to elucidate the formation of these anticyclones and the role of diabatic processes, we trace air parcels backwards from the upper-tropospheric anticyclones and quantify the diabatic heating in these air parcels. Around $25 \%-45 \%$ of the air parcels are diabatically heated during the last $3 \mathrm{~d}$ prior to their arrival in the upper-tropospheric anticyclones, and this amount increases to $35 \%-50 \%$ for the last $7 \mathrm{~d}$. The influence of diabatic heating is larger for heat-wave-related anticyclones in northern Europe and western Russia and smaller in southern Europe. Interestingly, the diabatic heating occurs in two geographically separated air streams; $3 \mathrm{~d}$ prior to arrival, one heating branch (remote branch) is located above the western North Atlantic, and the other heating branch (nearby branch) is located over northwestern Africa and Europe to the southwest of the target upper-tropospheric anticyclone. The diabatic heating in the remote branch is related to warm conveyor belts in North Atlantic cyclones upstream of the evolving upper-level ridge. In contrast, the nearby branch is diabatically heated by convection, as indicated by elevated mixed-layer convective available potential energy along the western side of the matured upper-level ridge. Most European regions are influenced by both branches, whereas western Russia is predominantly affected by the nearby branch. The remote branch predominantly affects the formation of the upper-tropospheric anticyclone, and therefore of the heat wave, whereas the nearby branch is more active during its maintenance. For long-
\end{abstract}

lasting heat waves, the remote branch regenerates. The results from this study show that the dynamical processes leading to heat waves may be sensitive to small-scale microphysical and convective processes, whose accurate representation in models is thus supposed to be crucial for heat wave predictions on weather and climate timescales.

\section{Introduction}

Among various kinds of natural hazards, temperature extremes and especially heat waves during summer impose large impacts particularly on human health (Horton et al., 2016; Watts et al., 2018). Anthropogenic climate change has already increased the number of heat wave days during the last decades (Perkins et al., 2012), which is in line with an overall global-scale temperature increase (Horton et al., 2015). Some regions, e.g. Europe, encounter changes in the frequency, persistence and maximum duration of regional circulation patterns associated with extreme temperatures (Horton et al., 2015). It is therefore crucial to understand the processes that lead to the formation and maintenance of these circulation patterns.

Recently, Zschenderlein et al. (2019) provided an analysis of European heat waves, and in all subregions considered, from the Iberian Peninsula to western Russia, these heat waves were associated with either an upper-tropospheric ridge or a blocking flow pattern. Several earlier studies emphasised that heat waves in the midlatitudes are typically colocated with atmospheric blocking (Carril et al., 2008; Pfahl 
and Wernli, 2012; Pfahl, 2014; Stefanon et al., 2012; Tomczyk and Bednorz, 2019). Heat waves in southern and central Europe are often caused by intense subtropical ridges extending to southern Europe (Sousa et al., 2018) or by a displacement of a North Atlantic subtropical high to central Europe (Garcia-Herrera et al., 2010). Both blockings and intense ridges are associated with anticyclonic flow anomalies in the upper troposphere, and these anticyclones are essential for the persistence of the events and for the strong downwelling associated with intense adiabatic warming of the air parcels (Zschenderlein et al., 2019). Upper-tropospheric anticyclones can therefore be regarded as an essential dynamic precursor for the formation of surface heat waves. As a continuation of Zschenderlein et al. (2019), we here aim to investigate the formation of these anticyclones in a Lagrangian and potential vorticity (PV) framework.

Both blockings and subtropical highs are associated with negative PV anomalies in the upper troposphere (Schwierz et al., 2004). These anomalies are the result of isentropic advection of low-PV air or cross-isentropic transport of low-PV air along moist ascending air streams. The isentropic advection of low-PV air corresponds to (i) the mechanism introduced by Yamazaki and Itoh (2013), in which blocking is maintained by the absorption of synoptic-scale anticyclones, or (ii) the quasi-adiabatic transport of air from lower latitudes, often ahead of extratropical cyclones (e.g. Colucci, 1985). Pfahl et al. (2015) and Steinfeld and Pfahl (2019) investigated, in a Lagrangian framework, the influence of diabatic heating on the formation and maintenance of blocking. Up to $45 \%$ of the air masses in northern hemispheric blocks experience latent heating by more than $2 \mathrm{~K}$ during the $3 \mathrm{~d}$ prior to their arrival in the block, and this percentage increases up to $70 \%$ when considering a $7 \mathrm{~d}$ period (Pfahl et al., 2015). The contribution of latent heating to the formation and maintenance of blocking is not uniform. Latent heating is more important for the onset than for the maintenance of the block (Pfahl et al., 2015). And in northern hemispheric winter, the contribution of latent heating is much larger for blocks over the oceans than for continental blocks, while in summer also continental blocks are substantially affected by latent heating (Steinfeld and Pfahl, 2019).

Latent heating due to condensation of water vapour is not only restricted to the formation of blocking; it generally influences the upper-level ridge building and amplification (e.g. Pomroy and Thorpe, 2000; Grams et al., 2011). In the midlatitudes, synoptic-scale latent heating occurs within moist ascending air streams from the lower to the upper troposphere, so-called warm conveyor belts (WCBs; Green et al., 1966; Harrold, 1973; Browning et al., 1973). The outflow of the WCB produces negative PV anomalies at the level of the midlatitude jet stream and is therefore a key process for upper-level ridge building (Madonna et al., 2014).

Recent climatological studies on blocking tend to be dominated by oceanic blocking (Pfahl et al., 2015; Steinfeld and Pfahl, 2019), but heat waves are typically associated with summertime continental blocks (Röthlisberger et al., 2016; Brunner et al., 2018; Chan et al., 2019), which are typically weaker than wintertime oceanic blocks (Pfahl and Wernli, 2012). Also, the influence of latent heating on the formation of continental blocking may differ. Quinting and Reeder (2017) analysed trajectories reaching the lower and upper troposphere during heat waves over southeastern Australia. They emphasised the influence of cloud-diabatic processes over a baroclinic zone to the south of the Australian continent on the formation of upper-tropospheric anticyclones. However, Quinting and Reeder (2017) did not analyse the life cycle of upper-tropospheric anticyclones, i.e. whether the role of diabatic heating differs between the formation and maintenance of these anticyclones. Since Quinting and Reeder (2017) focused on Australia and no similar study exists for Europe, we therefore aim to analyse the role of diabatic heating in the formation and maintenance of upper-tropospheric anticyclones associated with heat waves in different parts of Europe. We apply an impact-oriented perspective, meaning that we study a particularly impact-related type of uppertropospheric flow anomalies. The following questions are addressed:

1. What are typical source regions of low-PV air masses that constitute the upper-tropospheric anticyclones associated with European summer heat waves?

2. Are there inter-regional differences in the contribution of diabatic heating to the formation of these anticyclones?

3. Where and in which synoptic environment does the diabatic heating occur in airflows entering the anticyclones?

4. Are there differences in the relevance of diabatic heating during the formation and maintenance of the anticyclones?

Section 2 provides an overview of the data and methods employed in this study. Section 3, "Results", starts with a discussion of the origin of the air parcels arriving in the upper-tropospheric anticyclones, followed by a comparison of different regions in Europe. Subsequently, the locations of strong diabatic heating and their synoptic environments are presented. The results section closes with a comparison of the formation and maintenance of upper-tropospheric anticyclones. In Sect. 4, a summary of the main findings and avenues for further research are presented.

\section{Data and methods}

This section first describes the identification of uppertropospheric anticyclones and their connection to the heat waves at the surface. Secondly, the calculation of the trajectories and the identification of diabatic processes are outlined. If not noted otherwise, all analyses are based on the 
(a)

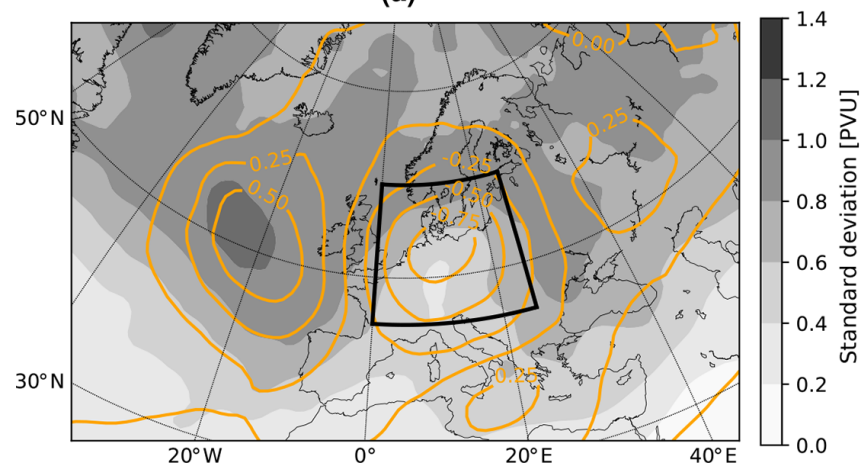

(b)

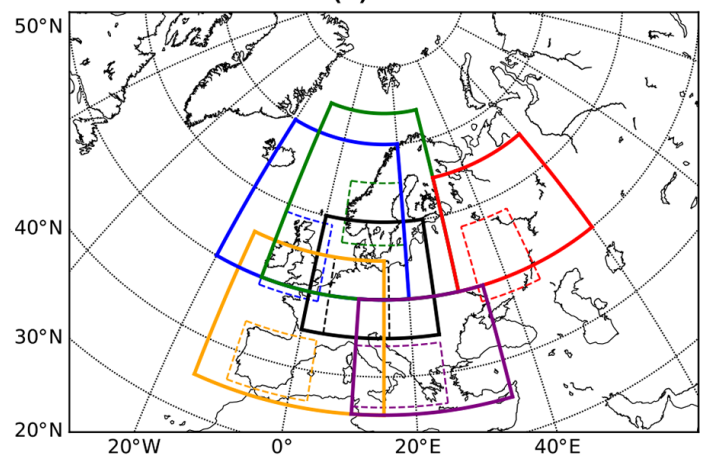

Figure 1. Identification of upper-tropospheric anticyclones. (a) Composite of the instantaneous, vertically averaged PV anomalies (VIPa) for all heat wave days in central Europe. The contours show the mean of VIPa (in PVU), and the shading shows the standard deviation of VIPa. (b) The solid boxes depict the regions where the upper-tropospheric PV anomalies are assigned to heat waves at the surface, and the dashed boxes show the regions of the heat waves as defined in Zschenderlein et al. (2019): Scandinavia (green), western Russia (red), Greece-Italy (purple), the Iberian Peninsula (orange), central Europe (black; also in a) and the British Isles (blue).

ERA-Interim reanalysis of the European Centre for MediumRange Weather Forecasts (ECMWF; Dee et al., 2011) on a $1^{\circ} \times 1^{\circ}$ longitude-latitude grid. To be consistent with Zschenderlein et al. (2019), we use the period between 1979 and 2016.

\subsection{Identification of upper-tropospheric anticyclones}

We aim to assign the surface heat waves in the six European regions (dashed boxes in Fig. 1b) used in Zschenderlein et al. (2019) to upper-tropospheric anticyclones. As an example, 73 heat waves are identified for central Europe (Zschenderlein et al., 2019). In order to define upper-tropospheric anticyclones, we use a PV approach introduced by Schwierz et al. (2004) that is based on the anomaly of the instantaneous, vertically averaged PV between 500 and $150 \mathrm{hPa}$ with respect to the monthly climatology. To be identified as an upper-tropospheric anticyclone, the PV anomaly at a grid point must fall below -0.7 PVU ( $1 \mathrm{PVU}=10^{-6} \mathrm{~K} \mathrm{~kg}^{-1} \mathrm{~m}^{2} \mathrm{~s}^{-1}$ ). Pfahl and Wernli (2012) used this threshold for the definition of weak blocking and demonstrated that the link between weak blocking and northern hemispheric warm temperature extremes is particularly robust. We therefore choose the -0.7 PVU threshold for defining upper-tropospheric anticyclones. Note that our definition of upper-tropospheric anticyclones requires no temporal persistence, in contrast to Schwierz et al. (2004), and is only constrained by the duration of the surface heat waves (at least $3 \mathrm{~d}$ ).

In a second step, we assign the upper-tropospheric anticyclone to the respective region. Exemplarily for central Europe, Fig. 1a depicts a composite of the vertically averaged PV anomaly for all heat wave days. The composite shows a negative upper-tropospheric PV anomaly, with small standard deviations over central Europe. In order to study the formation of the corresponding anticyclones, we define a rectangular box enclosing the $-0.5 \mathrm{PVU}$ contour line in the composite (black solid box in Fig. 1a) and assign all uppertropospheric negative PV anomalies in this box to heat waves in central Europe. The respective boxes for the other regions are shown in Fig. 1b. All grid points with PV anomalies below $-0.7 \mathrm{PVU}$ in the respective box during heat wave days in the corresponding region (dashed boxes in Fig. 1b) are identified as upper-tropospheric anticyclones.

\subsection{Backward trajectories}

Seven-day backward trajectories, driven by threedimensional ERA-Interim wind fields on 60 vertical model levels, are calculated at each 6-hourly time step with LAGRANTO (Sprenger and Wernli, 2015) for every heat wave day. Trajectories are initialised in the uppertropospheric anticyclone and started from an equidistant grid ( $\Delta x=100 \mathrm{~km}$ horizontally) and vertically between 500 and $150 \mathrm{hPa}$ every $50 \mathrm{hPa}$, with the additional criterion that the $\mathrm{PV}$ at the respective level must be less than $1 \mathrm{PVU}$. The latter excludes starting points in the stratosphere, similar to Steinfeld and Pfahl (2019). Physical parameters traced along the trajectories include temperature and potential temperature. The total number of trajectories is between 700000 for Greece-Italy and nearly 2000000 for Scandinavia.

In order to quantify diabatic processes along the trajectories, we evaluate whether diabatic heating or cooling dominates. For that, we calculate the highest $\left(\theta_{\max }\right)$ and lowest potential temperature $\left(\theta_{\min }\right)$ along the backward trajectories over a 3 or $7 \mathrm{~d}$ period. Diabatic heating is calculated as the difference $(\Delta \theta)$ between $\theta_{\max }$ and the preceding, i.e. closer to the origin, potential temperature minimum, whereas diabatic cooling is quantified as the difference $(\Delta \theta)$ between $\theta_{\min }$ and the preceding potential temperature maximum. If the diabatic heating exceeds the absolute value of the diabatic cooling, the trajectory belongs to the heating branch and vice versa. If 

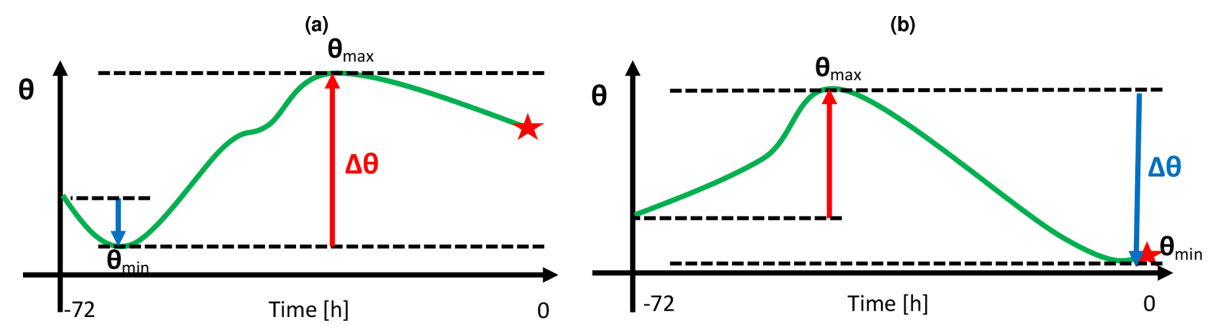

Figure 2. This schematic depicts the potential temperature change $\Delta \theta$ for a $3 \mathrm{~d}$ period. The red star indicates the starting point of the backward trajectory. (a) Diabatic heating (red arrow) exceeds diabatic cooling (blue arrow). (b) Diabatic cooling exceeds diabatic heating.

the magnitude of diabatic cooling and heating are equal, the trajectory will be sorted in the cooling branch. This approach is similar to Steinfeld and Pfahl (2019), with the difference that in their study all trajectories heated by more than $2 \mathrm{~K}$ are categorised as "diabatically heated", no matter how large the diabatic cooling is.

Figure 2 shows an example for a $3 \mathrm{~d}$ period: the backward trajectory in Fig. 2a experiences stronger diabatic heating (red arrow in Fig. 2a) than cooling (blue arrow in Fig. 2a) and therefore belongs to the heating branch, whereas in Fig. $2 b$ the diabatic cooling dominates and the trajectory is consequently sorted in the cooling branch.

\subsection{Feature composites}

To explore the synoptic environment in which the air parcels in the heating regime are diabatically heated, we create composites of various features centred around the location of maximum diabatic heating. We show PV at $330 \mathrm{~K}$, wind at $800 \mathrm{hPa}$, mixed-layer convective available potential energy (ML CAPE), and convective and large-scale precipitation. Whereas convective precipitation in ERA-Interim comes from the parameterised shallow, mid-level and deep convection, large-scale, i.e. stratiform, precipitation denotes the contribution coming from the cloud scheme (Dee et al., 2011). Flow features, i.e. blocks, cyclones and warm conveyor belts, are taken from Sprenger et al. (2017). In their climatology, weak atmospheric blocking is defined as a region where the anomaly of vertically averaged PV between 500 and $150 \mathrm{hPa}$ is lower than $-0.7 \mathrm{PVU}$ and persists for at least $5 \mathrm{~d}$ (Schwierz et al., 2004; Croci-Maspoli et al., 2007). Hence, temporal persistence is required in addition to our definition of upper-level anticyclones. The region affected by a cyclone is defined as the region within the outermost closed sea level pressure isoline surrounding one or several local sea level pressure minima (Wernli and Schwierz, 2006). Warm conveyor belts are air parcel trajectories ascending more than $600 \mathrm{hPa}$ in $2 \mathrm{~d}$ associated with a midlatitude cyclone (Madonna et al., 2014). A more detailed description of the three features is given in Sprenger et al. (2017). To assess whether the occurrence of blocks, cyclones and WCBs is anomalous, we compare the frequencies of the three features during diabatic heating with their climatological frequencies.
The anomaly is then defined as the difference between the observed frequency during heat wave days and the climatological frequency.

\section{Results}

\subsection{Source regions of low-PV air masses}

This section focuses on the origin of trajectories started from the upper-tropospheric anticyclones. To this end, density maps of trajectory locations at specific time steps are created, which show relative frequencies and are normalised such that the spatial integral over the whole distribution yields $100 \%$. We only present the density maps for heat waves in central Europe, western Russia and Greece-Italy because they exhibit the largest differences. Results for the other three regions, viz. the Iberian Peninsula, British Isles and Scandinavia, are shown in the Supplement (Figs. S1 and S2).

Three days prior to the arrival of the trajectories in the upper-tropospheric anticyclone over central Europe, one part of the heating branch is located over the western North Atlantic and the other part over northwestern Africa in the middle and partly lower troposphere (Fig. 3a). The western North Atlantic is a typical source region of diabatically heated trajectories for the formation of atmospheric blocking, although the main source region in summer is shifted towards North America (Pfahl et al., 2015). In the blocking study by Pfahl et al. (2015), most of the backward trajectories were initialised over the North Atlantic to the west of central Europe, which explains the westward shift of the source regions of diabatically heated trajectories compared to our study. Additionally, the western North Atlantic is the entrance region of the summer storm tracks (Dong et al., 2013) and therefore a region prone to diabatic heating. The second major source region over northwestern Africa (Fig. 3a) is not known as a source region for air parcels influencing the formation of blocking, presumably due to the stronger influence of oceanic blocks in other studies (e.g. Pfahl et al., 2015; Steinfeld and Pfahl, 2019), but appears to be important for the formation of summertime upper-tropospheric anticyclones in association with heat waves. Due to this separation of the heating branch into two distinct regions, trajectories in 
(a)

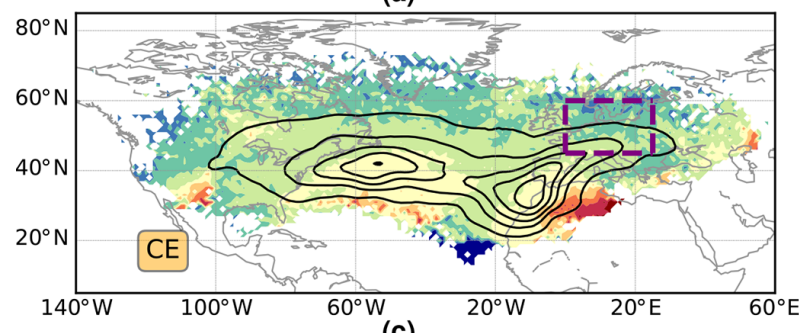

(c)

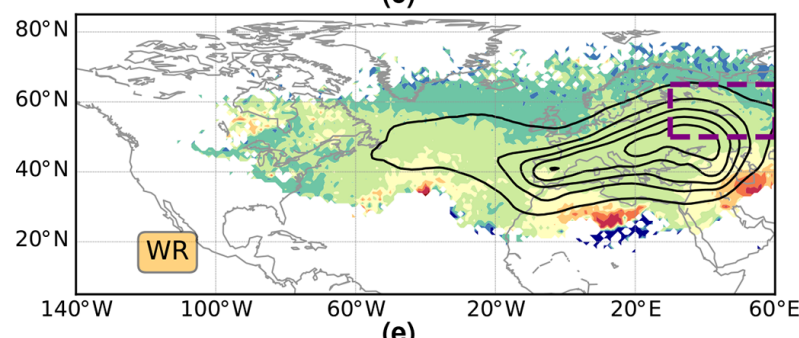

(e)

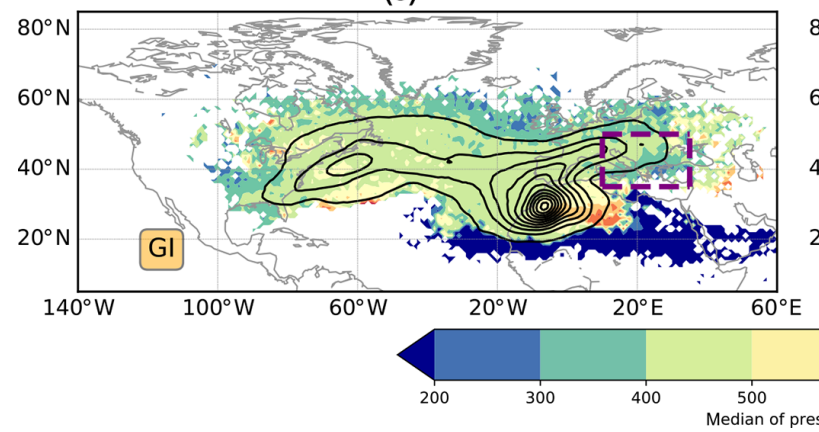

(b)

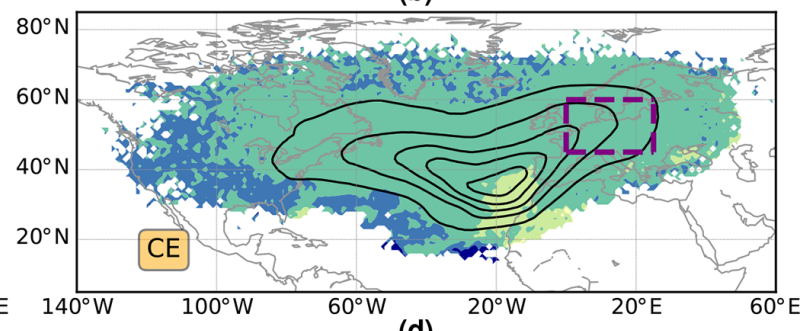

(d)

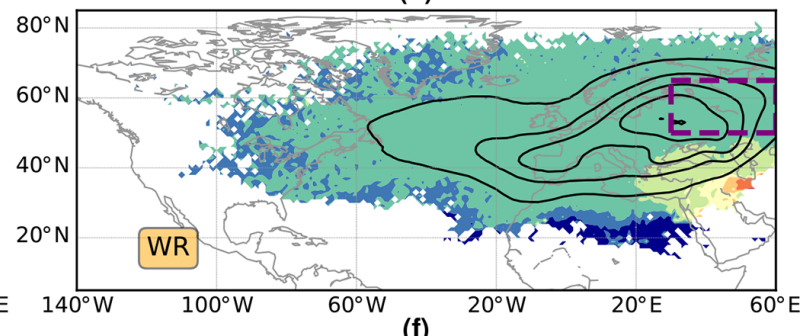

(f)

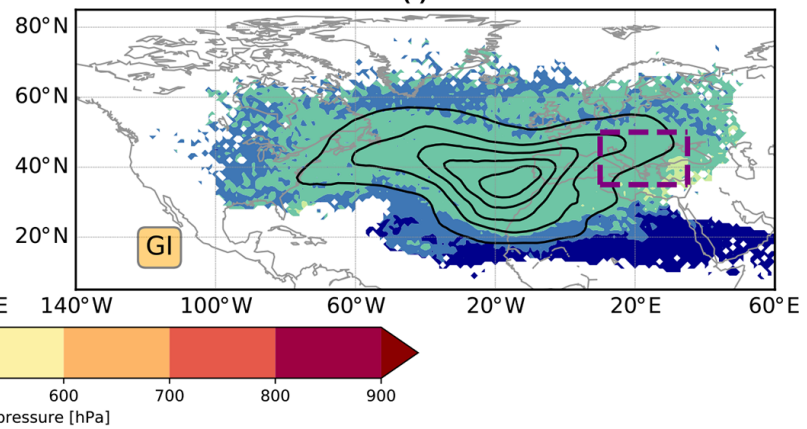

Figure 3. Spatial distribution of diabatically heated $(\mathbf{a}, \mathbf{c}, \mathbf{e})$ and cooled $(\mathbf{b}, \mathbf{d}, \mathbf{f})$ trajectories $3 \mathrm{~d}$ prior to arrival in the upper-tropospheric anticyclones for (a, b) central Europe (CE), (c, d) western Russia (WR) and (e, f) Greece-Italy (GI). The colours indicate the median pressure of air parcels, and contours display the air parcel density (starting from $1 \%$ per $10^{5} \mathrm{~km}^{2}$ in $2 \%$ increments). The dashed purple boxes represent the area in which upper-tropospheric anticyclones are associated with heat waves (see Sect. 2.1 and Fig. 1b).

the heating branch located west and east of $30^{\circ} \mathrm{W} 3 \mathrm{~d}$ prior to the arrival in the upper-tropospheric anticyclone are analysed separately in the following and are hereafter denoted as the remote and nearby heating branch, respectively.

Air parcels in the cooling branch related to uppertropospheric anticyclones above central European heat waves are located not only in the upper troposphere at around 300$400 \mathrm{hPa}$ and mostly above northwestern Africa but also over the North Atlantic and already within the upper-level anticyclone area $3 \mathrm{~d}$ prior to their arrival (Fig. 3b). These air parcels are then transported northwards to central Europe along the western flank of the ridge associated with the heat wave. Pfahl et al. (2015) showed that the majority of the air parcels not influenced by diabatic heating (comparable to our cooling branch) are, $3 \mathrm{~d}$ prior to the arrival in the block, located to the east of the diabatically heated trajectories. This is also the case here when comparing the location of the cooling with the remote heating branch (Fig. 3a and b).

Seven days prior to the arrival of the air parcels in the heating branch to central Europe, most of them are located above North America and the western North Atlantic and to some extent above northwestern Africa. Compared to the $3 \mathrm{~d}$ period, air parcels are located at lower altitudes (Fig. 4a). Generally, air parcels in the subtropics over the North Atlantic and Gulf of Mexico are located at lower altitudes compared to air parcels above the North American continent and towards the eastern Pacific. Air parcels in the cooling branch are at similar pressure levels compared to the $3 \mathrm{~d}$ period but more widely distributed compared to the heating branch with a maximum density above the North Atlantic (Fig. 4b). Similar to the $3 \mathrm{~d}$ timescale, the major part of the cooling branch is found east of the remote heating branch.

The density maps for air parcels in the heating branch reaching western Russia exhibit two distinct differences compared to central Europe. Firstly, the source regions of the heating branch do not show two clearly separated geographical maxima on the $3 \mathrm{~d}$ timescale (Fig. $3 \mathrm{c}$ ). In fact, the major part of this branch is located above the European continent and in the middle troposphere. However, on the $7 \mathrm{~d}$ timescale, a pattern of two geographical maxima emerges with the highest densities over the western North Atlantic and in the Mediterranean area (Fig. 4c). Secondly, more air 
(a)

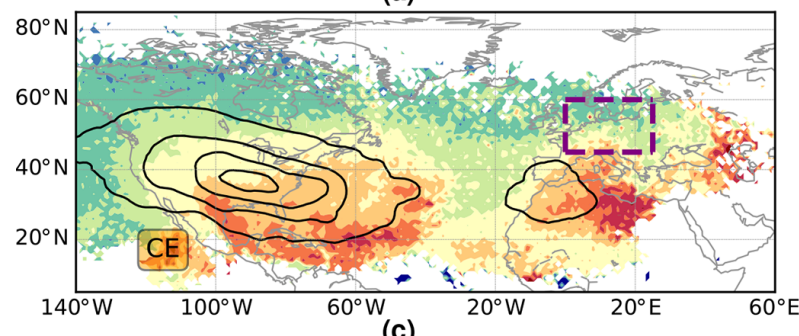

(c)

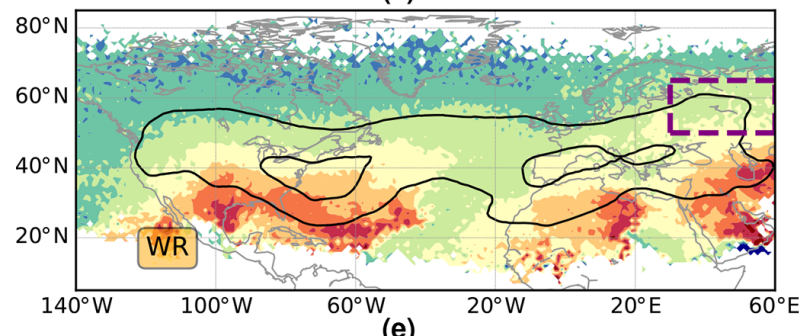

(e)

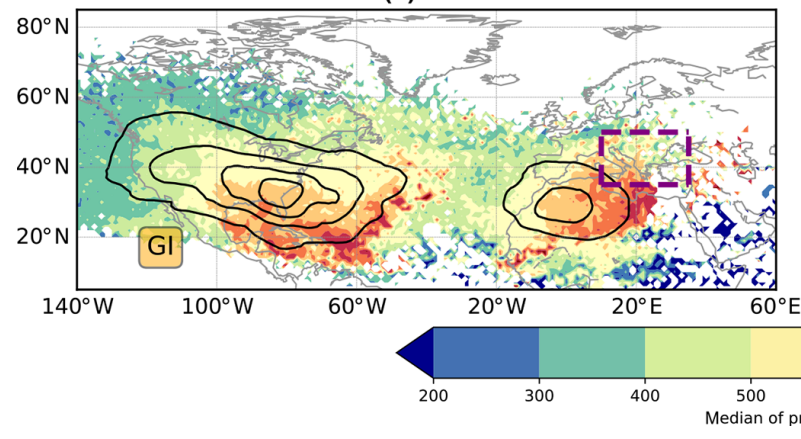

(b)

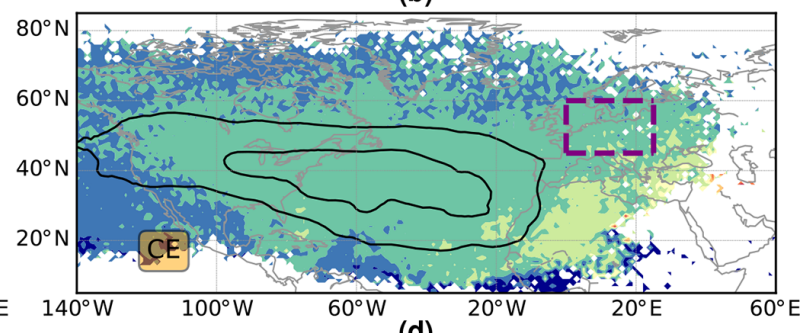

(d)

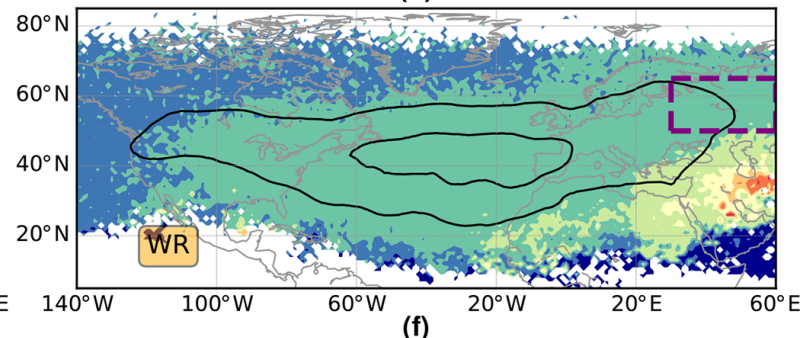

(f)

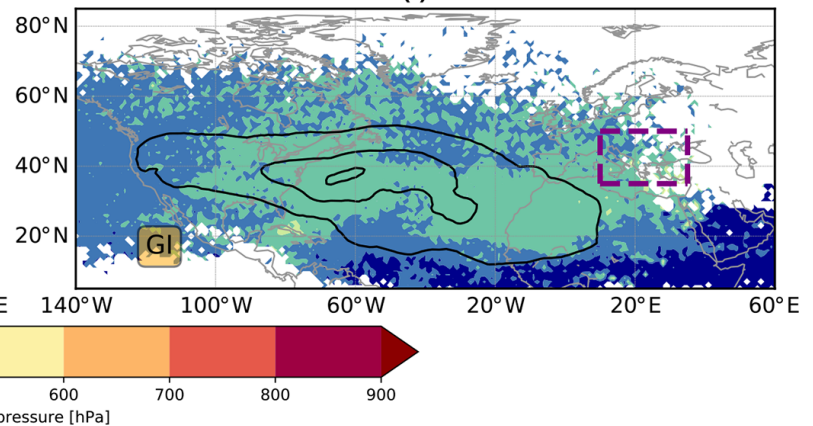

Figure 4. Same as Fig. 3 but for $7 \mathrm{~d}$ prior to arrival.

parcels are already located in the vicinity of the target upperlevel anticyclone, indicating that the diabatic heating can occur more locally. The overall pattern of the cooling branch, however, does not reveal substantial differences compared to the pattern for central Europe, although the maximum densities are generally shifted to the east (Figs. 3d and 4d).

Air parcels in the heating branch reaching the upper troposphere above Greece-Italy predominantly originate from northwestern Africa during the last $3 \mathrm{~d}$, in particular from the Atlas Mountains (Fig. 3e). Therefore, these anticyclones are strongly influenced by the nearby heating branch, whereas on the $7 \mathrm{~d}$ timescale, most of the diabatically heated trajectories originate from the western Atlantic and North America (Fig. 4e). The majority of the air parcels in the cooling branch are located above the North Atlantic 3 and $7 \mathrm{~d}$ prior to the heat wave, but some trajectories are located in the tropics south of $20^{\circ} \mathrm{N}$ at around $200 \mathrm{hPa}$ (Figs. 3f and 4f) - an area which is climatologically influenced by upper-level easterly winds in summer (Fink et al., 2017). In this region and during this time of the year, organised convection in the form of huge mesoscale convective systems occurs in the ITCZ (Intertropical Convergence Zone) over the West African monsoon region. Their upper-level poleward outflow turns east- ward to feed the subtropical jet over northern Africa and the Mediterranean (cf. Fig. 1 in Lafore et al., 2010).

Three days prior to the arrival of the air parcels in the heating branch over the Iberian Peninsula and the British Isles, most of them are located above the western North Atlantic in the middle and lower troposphere, but some are also located over northwestern Africa and Spain (Fig. S1a and c). For Scandinavia, air parcels are located over the western North Atlantic and southern and central Europe in nearly equal parts (Fig. S1e). On the $7 \mathrm{~d}$ timescale, air parcels of the heating branch are distributed between North America and the western Atlantic (Fig. S2a and c), although the dichotomy in the trajectory origin for Scandinavia still exists (Fig. S2e). The results for the cooling branches are qualitatively similar to the other regions (Figs. S1b, d, and S2b, d, f), while for Scandinavia, a large fraction of diabatically cooled air parcels is already located in the target area $3 \mathrm{~d}$ prior to arrival (Fig. S1f).

\subsection{Two diabatic regimes}

We now compare the statistical distributions of the potential temperature changes in the heating and cooling branch. Changes in potential temperature during the last 3 and $7 \mathrm{~d}$ 
(a)

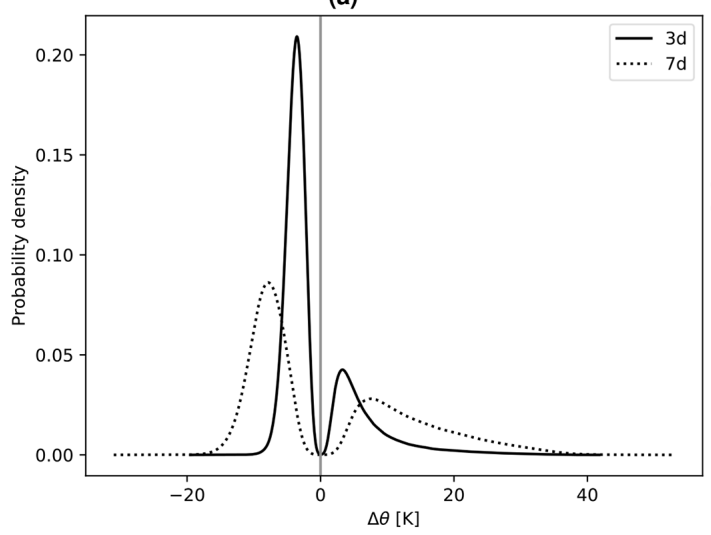

(b)

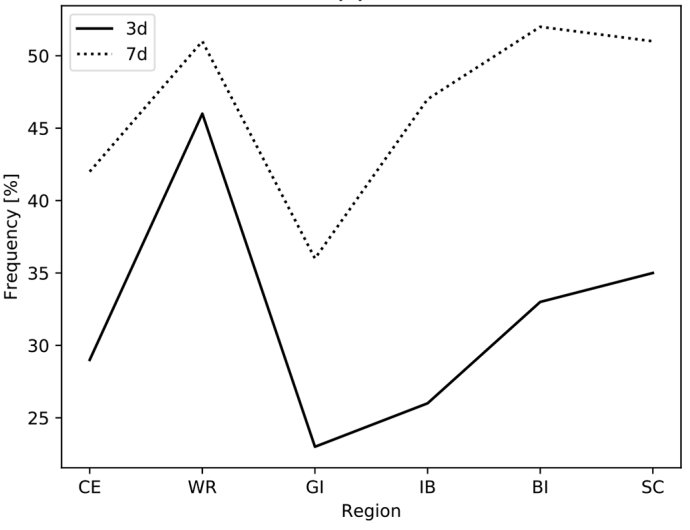

Figure 5. Diabatic processes in the heating and cooling branches 3 (solid line) and $7 \mathrm{~d}$ (dashed line) before reaching upper-tropospheric anticyclones. (a) Probability density distribution of the potential temperature changes for air parcels reaching central European heat wave anticyclones. The grey line denotes the $0 \mathrm{~K}$ border separating the heating and cooling branch. (b) Fraction of diabatically heated trajectories for all regions (CE: central Europe; WR: western Russia; GI: Greece-Italy; IB: Iberian Peninsula; BI: British Isles; SC: Scandinavia).

prior to reaching upper-tropospheric anticyclones over central Europe are shown as probability density distributions. For both the 3 and $7 \mathrm{~d}$ period, the shape of the cooling branch features a Gaussian normal distribution, whereas the heating branch is more skewed (Fig. 5a). This skewness increases for the $7 \mathrm{~d}$ period, implying an overall higher magnitude of diabatic heating along the trajectories on this timescale. During the last $3 \mathrm{~d}$, about $29 \%$ of the trajectories are influenced by diabatic heating and, consequently, $71 \%$ belong to the cooling branch (Fig. 5b). On the $7 \mathrm{~d}$ timescale, $42 \%$ of the trajectories are in the heating branch (Fig. 5b). Hence, diabatic heating along trajectories substantially influences the formation of upper-tropospheric anticyclones above central Europe.

The majority of trajectories in the cooling branch slightly descend and are radiatively cooled in the free atmosphere, while most of the trajectories in the heating branch ascend (not shown). Overall, the diabatic heating is a more rapid process compared to the diabatic cooling (not shown). Therefore, the heating branch can be interpreted as a strongly cross-isentropic branch transporting low-PV air from the lower to the upper troposphere, whereas the cooling branch is a quasi-adiabatic process that advects low-PV air towards the upper-tropospheric anticyclone, in line with the analysis of Pfahl et al. (2015) and Steinfeld and Pfahl (2019) for blocks.

The cross-isentropic transport of low-PV air from the lower to the upper troposphere in the heating branch is stronger for western Russia. During the last $3 \mathrm{~d}$, about $44 \%$ of the air parcels reaching upper-tropospheric anticyclones above western Russia are affected by the heating branch, which is the highest fraction among the different European regions (Fig. 5b). For Scandinavia and the British Isles, about $35 \%$ of the air parcels are influenced by diabatic heating, which is slightly more than for central Europe. The Mediter- ranean area, i.e. Greece-Italy and the Iberian Peninsula, however, is less influenced by the heating branch, with only about $25 \%$ of the trajectories in this branch on the $3 \mathrm{~d}$ timescale. During the last $7 \mathrm{~d}$, the relevance of the heating branch increases for all regions (Fig. 5b). The highest influence of the heating branch (about 50\%) is found for trajectories reaching upper-tropospheric anticyclones above the British Isles, Scandinavia and western Russia. Interestingly, the increase in the fraction of diabatically heated air parcels from the 3 to the $7 \mathrm{~d}$ period is smallest for western Russia, indicating that heat wave anticyclones in western Russia are less influenced by remote diabatic heating beyond $3 \mathrm{~d}$ prior to their arrival in the anticyclone.

Comparing the fraction of diabatically heated air parcels contributing to the formation of atmospheric blocks (Pfahl et al., 2015) with our findings, we conclude that the fraction is lower in our study. This can be explained by three main reasons: firstly, weather systems that are associated with diabatic heating such as extratropical cyclones and warm conveyor belts are climatologically less frequent during summer (Madonna et al., 2014). Secondly, Pfahl et al. (2015) defined blocking with a more pronounced negative PV anomaly, and because more intense negative PV anomalies are associated with stronger latent heating in WCBs (Madonna et al., 2014), the influence of diabatically heated trajectories is reduced in our study. Thirdly, the quantification of diabatic heating along trajectories of Pfahl et al. (2015) is slightly different because they only quantified the contribution of diabatic heating to the formation of blocking and did not account for diabatic cooling.

\subsection{Two geographically separated heating branches}

In the remainder of this study, we further analyse the heating branches for heat wave anticyclones in three regions. Re- 
(a)

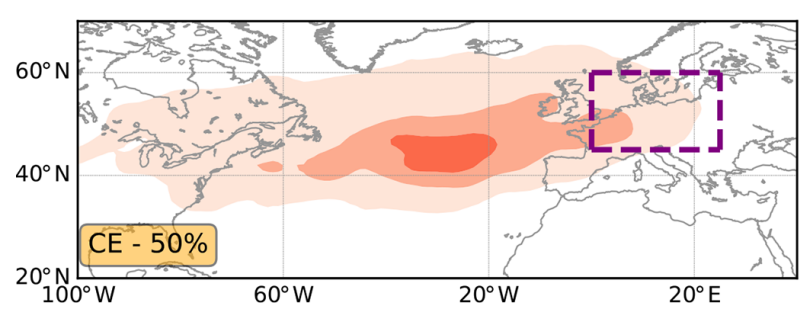

(c)

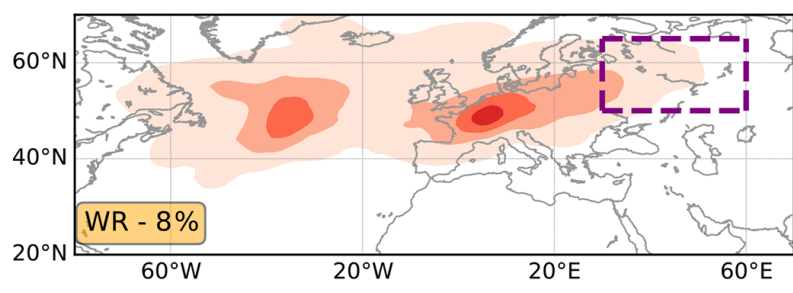

(e)
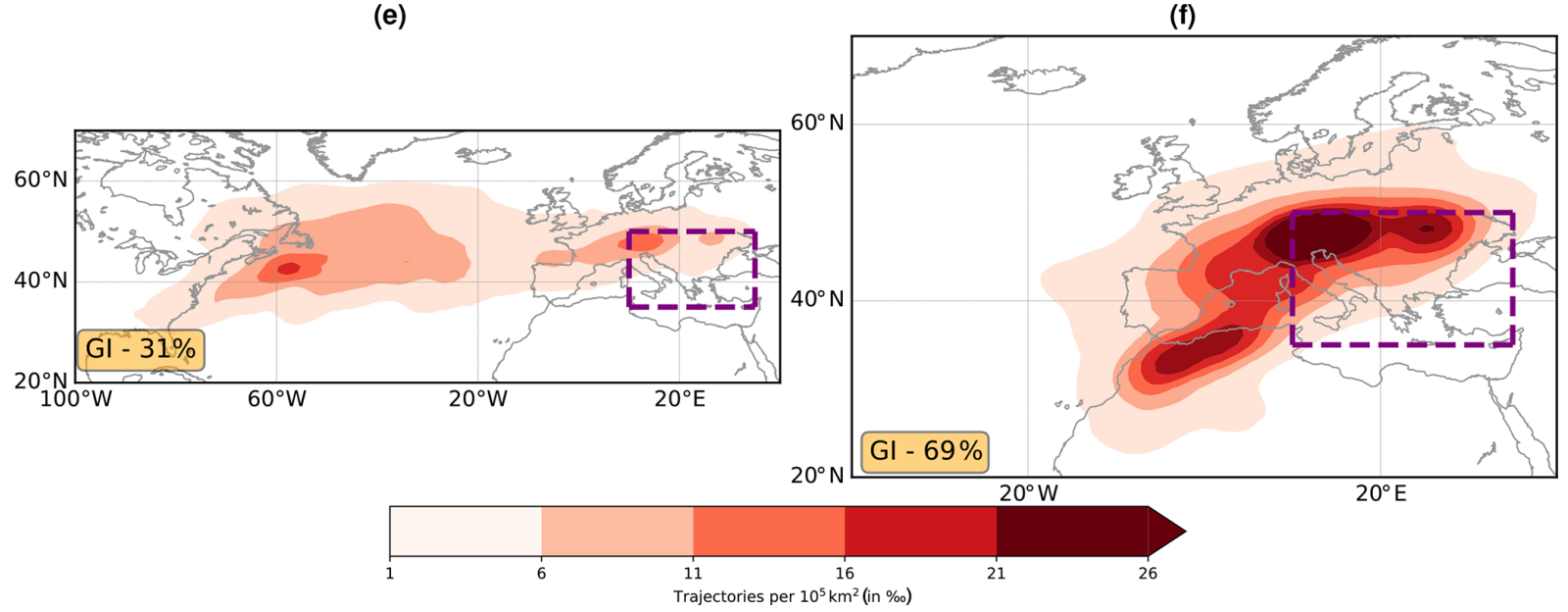

(b)

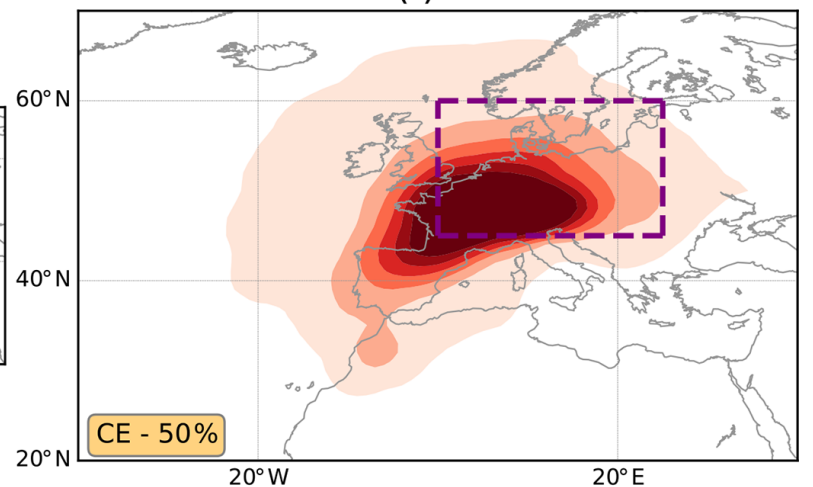

(d)

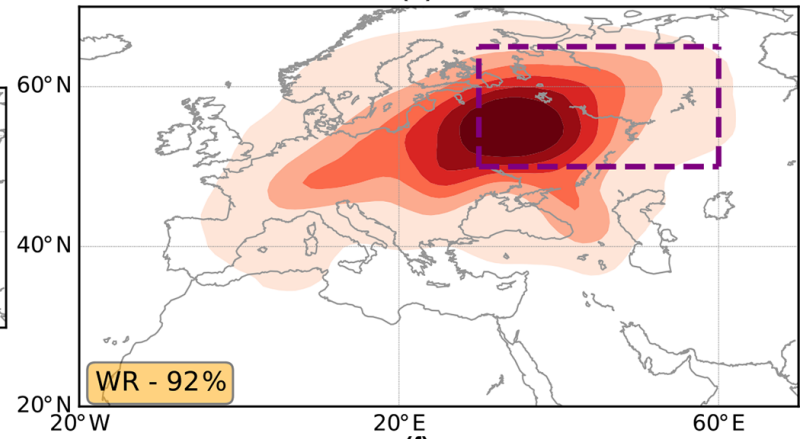

(f)

Figure 6. Geographic location of the maximum diabatic heating along trajectories for the remote (a, c, e) and nearby heating branch (b, d, f) during the last $3 \mathrm{~d}$ prior to reaching upper-tropospheric anticyclones above central Europe (CE), western Russia (WR) and Greece-Italy (GI). The percentages in the orange boxes denote the fraction of the remote and nearby heating branch with respect to the whole heating branch.

member that heated trajectories located west (east) of $30^{\circ} \mathrm{W}$ $3 \mathrm{~d}$ prior to the arrival in the heat wave anticyclone belong to the remote (nearby) heating branches. We focus on central Europe and Greece-Italy, which are affected by the nearby and remote heating branches (Fig. 3a and e), and on western Russia, which is affected predominantly by the nearby heating branch (Fig. 3c).

The spatial distributions of the locations of maximum diabatic heating along the trajectories for the nearby and remote heating branches are shown in Fig. 6. These locations are defined as the geographical positions at the end of the maxi- mum $6 \mathrm{~h}$ increase in potential temperature in the last $3 \mathrm{~d}$ prior to reaching the upper-level anticyclones. The remote heating branch associated with anticyclones above central Europe accounts for $50 \%$ of the whole heating branch. Most of its diabatic heating occurs over the central North Atlantic between $40-50^{\circ} \mathrm{N}$ and $20-40^{\circ} \mathrm{W}$ (Fig. 6a). Air parcels in the nearby heating branch are diabatically heated over the European continent in a similar latitude band (Fig. 6b). For western Russia, only $8 \%$ of the heated trajectories are in the remote branch, and the strongest diabatic heating occurs not only over the North Atlantic but also over central Europe (Fig. 6c). 

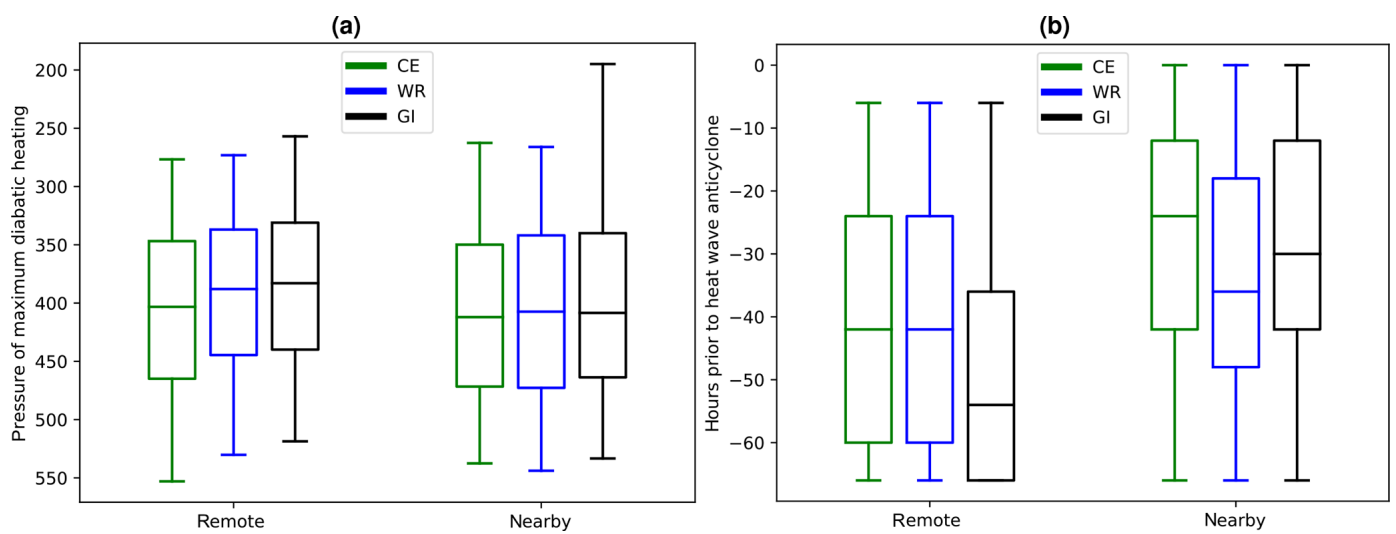

Figure 7. Pressure (a) and time (b) of maximum diabatic heating of trajectories in the two heating branches of the heat wave anticyclone over central Europe (green: CE), western Russia (blue: WR) and Greece-Italy (black: GI). Horizontal lines denote the median, the boxes the interquartile range, and the whiskers the 5 th and 95 th percentile.

The dominant heating branch reaching western Russia is the nearby heating branch (92\%; Fig. 6d). Most of the diabatic heating in this branch occurs over the European continent and mostly in the target area between 50 and $60^{\circ} \mathrm{N}$. For GreeceItaly, 69 (31) \% of the heated trajectories are assigned to the nearby (remote) heating branch. Air parcels in the remote heating branch experience diabatic heating over the western North Atlantic (Fig. 6e). Local maxima of diabatic heating in the nearby heating branch occur above the Atlas Mountains and the Alps (Fig. 6f), suggesting the importance of orographic ascent for the formation of upper-tropospheric anticyclones in this region. Overall, most of the diabatic heating in the nearby heating branch occurs close to the target region, whereas the remote heating branch is associated with more remote diabatic heating. Most of the trajectories are diabatically heated at around $400 \mathrm{hPa}$ (Fig. 7a), indicating that the air parcels are mostly heated due to latent heat release in clouds as opposed to surface fluxes.

The dominant remote branch associated with anticyclones above the Iberian Peninsula and the British Isles is diabatically heated above the central North Atlantic (Fig. S3a and c), similar to anticyclones over central Europe. Scandinavia is slightly more influenced by the nearby branch (Fig. S3e and f), and air parcels in this branch are diabatically heated above central and western Europe (Fig. S3f).

Although the remote and nearby heating branches are geographically separated, it may be possible that the maximum diabatic heating occurs at the same time before arrival in the upper-tropospheric anticyclone. Around 42 to $54 \mathrm{~h}$ prior to arrival, the remote heating branch experiences the strongest diabatic heating (Fig. 7b). On the contrary, trajectories in the nearby heating branch are strongly heated between 24 and $36 \mathrm{~h}$ prior to arrival (Fig. 7b). Hence, air parcels in the remote branch are heated earlier compared to the nearby branch.

To explore which synoptic systems lead to the ascent and latent heat release in the two different heating branches, we create composites of different fields and frequencies of blocks, cyclones and warm conveyor belts centred around the location of maximum diabatic heating. To emphasise the structure of the most pronounced heating, we only consider trajectories in the composites that are diabatically heated by more than $5 \mathrm{~K}$ during the last $3 \mathrm{~d}$.

The composite for the air parcels within the remote heating branch reaching central Europe is presented in Fig. 8. The upper-tropospheric circulation, represented by PV at $330 \mathrm{~K}$, is characterised by a trough upstream of the maximum diabatic heating (Fig. 8a). At the surface, extratropical cyclones are frequently located to the west and north of the diabatic heating maximum. The position of the extratropical cyclones west of the heating maximum is slightly east of the upper-level PV trough, which corresponds to the canonical configuration of cyclogenesis at the leading edge of an upper-tropospheric trough. In the warm sector of these cyclones, where southwesterly winds prevail (Fig. 8a), lifting occurs according to quasi-geostrophic forcing (Holton and Hakim, 2013). Hence, it is meaningful that warm conveyor belts are found centred around the diabatic heating maximum and downstream of the extratropical cyclones (Fig. 8a). These ascending air streams release latent heat and lead to an increase in potential temperature. Therefore, the remote heating branch is often influenced by cyclones in the North Atlantic storm track and latent heating in their warm conveyor belts.

Above the diabatic heating maximum, an upper-level ridge evolves and blocking frequencies are enhanced downstream (Fig. 8a). ML CAPE values are usually low in this branch. To the southwest of the diabatic heating maximum, ML CAPE values strongly increase due to climatologically higher sea surface temperatures in the western North Atlantic south of $30^{\circ} \mathrm{N}$.

To assess whether the occurrence of the three features in the North Atlantic region is anomalous for this time of the 
(a)

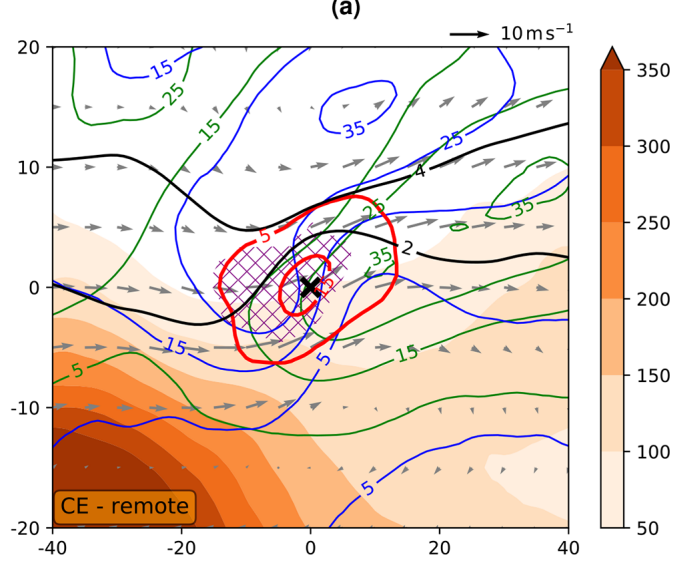

(b)

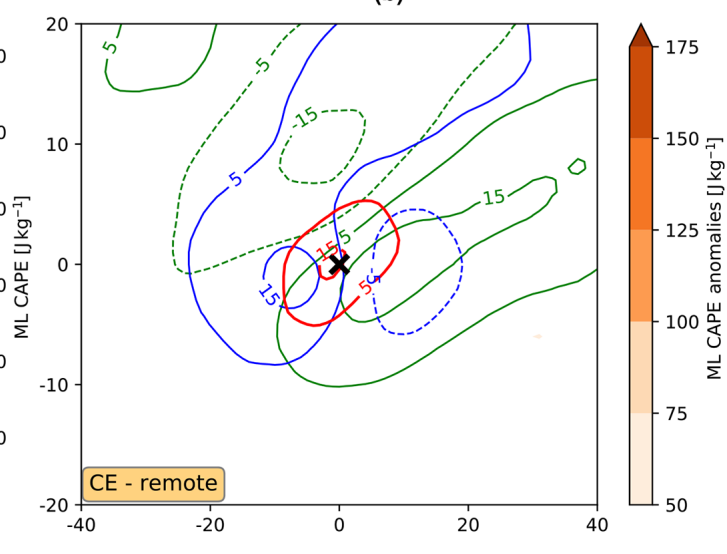

Figure 8. Composites centred around the position of maximum diabatic heating for the remote heating branch reaching upper-tropospheric anticyclones above central Europe. (a) Frequencies of extratropical cyclones (blue), blocks (green) and warm conveyor belts (red) starting from $5 \%$ in $10 \%$ increments. The orange shading shows the ML CAPE (in J kg${ }^{-1}$ ) and the arrows the wind at $800 \mathrm{hPa}$. Black contours indicate PV ( 2 and 4 PVU contours) at $330 \mathrm{~K}$. The purple hatching marks the region where the stratiform precipitation exceeds the convective precipitation (only for areas with total precipitation $\geq 2 \mathrm{~mm} \mathrm{~d}^{-1}$ ). (b) Anomalies of cyclone (blue), blocking (green) and warm conveyor belt (red) frequency.

year, we compare the frequencies of the three features during the diabatic heating with their climatological frequencies. In general, the anomalies of all three features attain their highest values in the vicinity of or at the position of the diabatic heating maximum (Fig. 8b). To the west and southwest of the diabatic heating maximum, the observed cyclone frequency is about 15 percentage points higher than the climatology, which is an increase by a factor of about 1.5 . In contrast, the anomalies of the cyclone frequency to the north are smaller, although the observed frequency is similar (Fig. 8a). As a result of the enhanced cyclone occurrence, also the existence of warm conveyor belts is anomalously high (Fig. 8b). In accordance with the anomalously high cyclone frequency north and northwest of the diabatic heating maximum, the blocking frequency is anomalously low in this region. Downstream of the diabatic heating maximum, the blocking frequencies are higher and the cyclone frequencies lower than climatologically expected.

Steinfeld and Pfahl (2019) performed a similar composite analysis for the latent heating associated with blocks and found a more pronounced upper-level ridge pattern due to similar reasons as discussed at the end of Sect. 3.2. Overall, the latent heating in the warm conveyor belts of extratropical cyclones is important for the formation of both atmospheric blocks and upper-tropospheric ridges associated with heat waves. Also Quinting and Reeder (2017) highlighted the role of cloud-diabatic processes and ascending air streams for upper-level anticyclones during heat waves in southeastern Australia. This is similar to the warm conveyor belts in our remote branches.

After discussing the synoptic conditions of the remote heating branch, we now focus on the conditions of the nearby heating branch. In this branch, the diabatic heating maximum is located below the western part of an upper-tropospheric anticyclone, which is much more pronounced compared to the remote heating branch (Fig. 9a and b). In contrast, the frequency of both cyclones and WCBs at the position of maximum diabatic heating is reduced (WCBs are not visible in Fig. 9a and $b$; they occur with frequencies of less than $3 \%$ ). Hence, the driving mechanisms of the latent heating differs between the two branches. The circulation at $800 \mathrm{hPa}$ is more anticyclonic and much weaker in the nearby compared to the remote heating branch. The most substantial difference between the two heating branches is the enhanced ML CAPE in the nearby heating branch (Fig. 9a and b), indicating the potential for convection. The absolute values of ML CAPE are, however, not extremely high, which may indicate that convection is efficiently depleting the ML CAPE. Additionally, according to ERA-Interim, most of the precipitation in the nearby heating branch is indeed convective (Fig. 9a; more clear for western Russia in Fig. 9b), whereas precipitation in the remote heating branch is predominantly stratiform (Fig. 8a). Cloud top temperatures derived from infrared satellite imagery are between -5 and $-9{ }^{\circ} \mathrm{C}$ at the location of maximum diabatic heating (not shown). Hence, we assume that in the nearby branch latent heating is driven by mid-level convection or deep convection that reaches from lower into mid-levels.

The anomalies underline the importance of the enhanced blocking frequencies and ML CAPE values for the nearby heating branch (Fig. 9c and d). Although the anomalies show also a small positive anomaly of cyclone frequencies (Fig. 9c and d), the absolute frequency (Fig. 9a and b) is lower compared to the remote heating branch (Fig. 8a). Comparing the two regions, western Russia shows slightly higher anomalies of blocking frequencies and ML CAPE at the location 


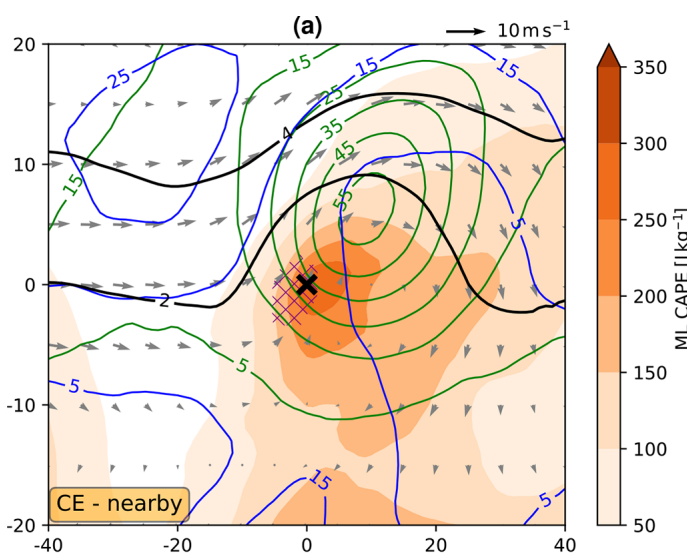

(c)
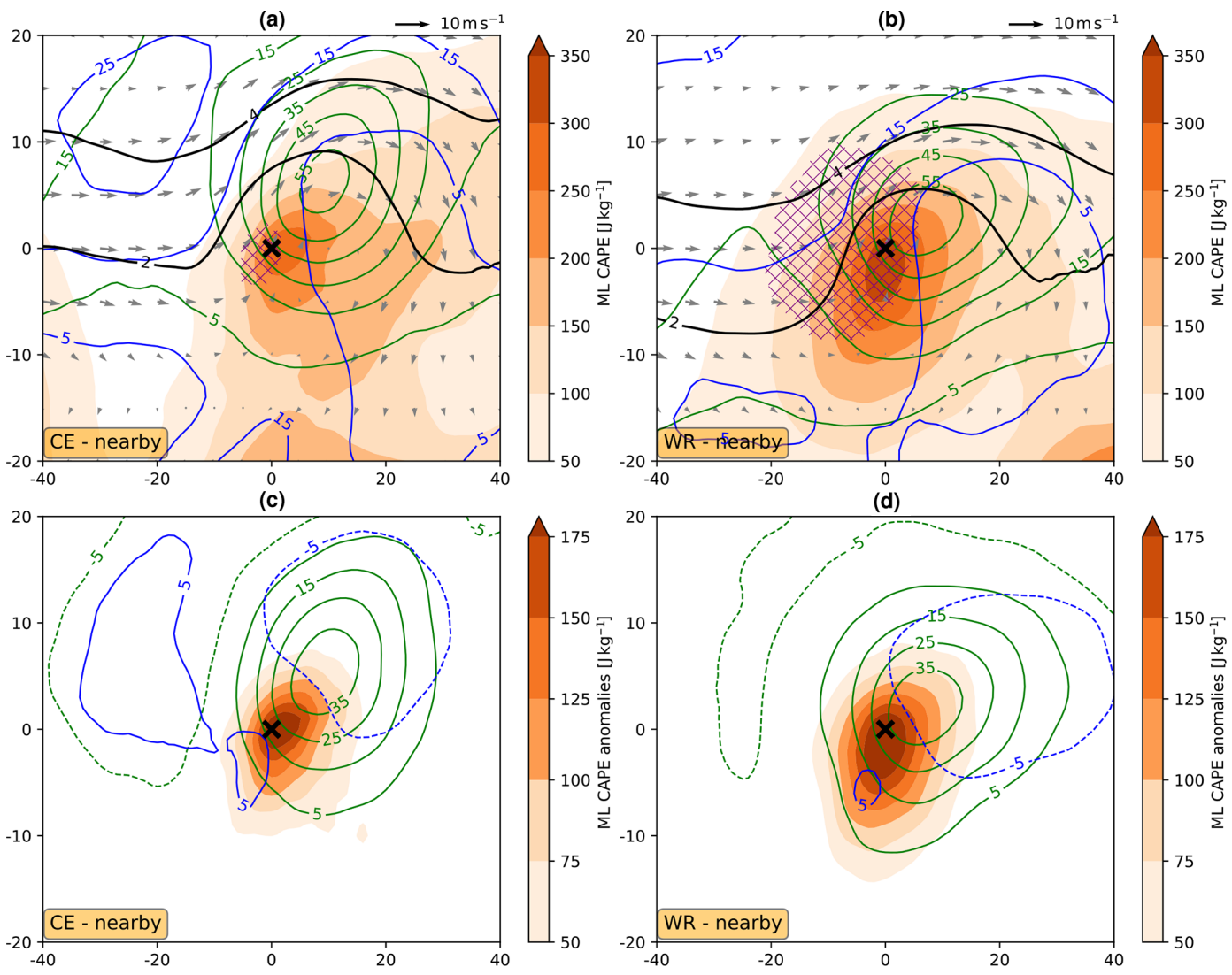

(d)

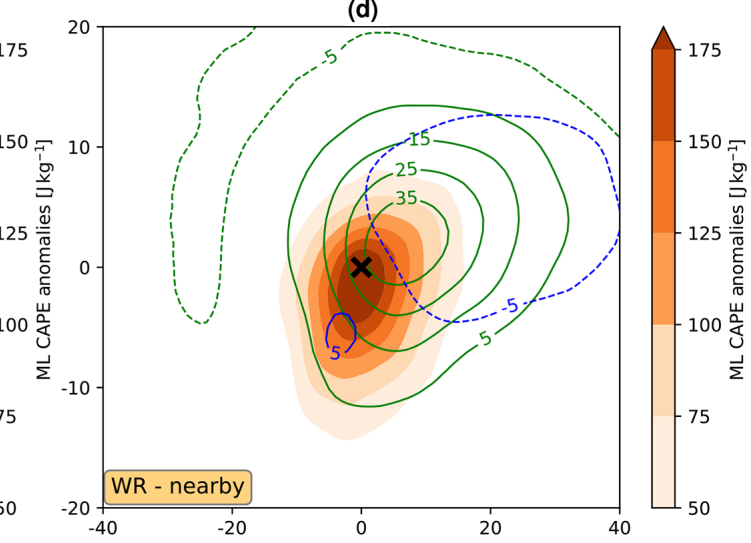

Figure 9. Same as Fig. 8 but for the nearby heating branch reaching central Europe (a, c) and western Russia (b, d). Note that WCB frequencies are not shown because they are negligible in the nearby branch. The top row shows the full fields and the bottom row the anomalies. The purple hatching marks, in contrast to Fig. 8, the area where the convective precipitation exceeds the stratiform precipitation (only for areas with total precipitation $\geq 2 \mathrm{~mm} \mathrm{~d}^{-1}$ ).

of maximum diabatic heating (Fig. 9d). The nearby heating branch has not yet been discussed in the literature on the formation of European blocking, but it appears to be relevant for the formation of upper-tropospheric anticyclones in association with heat waves in summer.

Trajectory-centred composites for the remote branch reaching anticyclones over western Russia, as well as for both heating branches arriving over the Iberian Peninsula, British Isles, Scandinavia and Greece-Italy, can be found in the Supplement (Figs. S4-S8). Overall, the composites are qualitatively similar to the already discussed ones, especially for the remote branches (panels $\mathrm{a}$ and $\mathrm{b}$ in Figs. 4-8) and only differ with respect to the magnitudes of ML CAPE in the nearby branch. ML CAPE values for Greece-Italy are comparable to those for western Russia, albeit in a smaller area (Fig. S8c and d), but generally lower for trajectories of the nearby branch reaching anticyclones over Scandinavia (Fig. S7c and d) or the British Isles (Fig. S6c and d). In addition, the upper-level ridge of the nearby branch reaching Scandinavia (Fig. S7c) is more pronounced compared to Greece-Italy (Fig. S8c). A similar difference in the magni- tude of the upper-level ridge is found for the remote branches (Figs. S7 and 8a).

\subsection{Diabatic heating during the life cycle of heat waves}

Here, we investigate the life cycle of the upper-tropospheric anticyclones associated with heat waves, i.e. the temporal sequence of the occurrence of the different heating branches. The contributions of the nearby and remote heating branches and their relative importance with respect to the whole heating branch are quantified as a function of the duration of the heat waves. We concentrate on the results for central Europe because this region is equally affected by both branches. Due to the definition of the heat waves (cf. Zschenderlein et al., 2019), all events have a minimum duration of $3 \mathrm{~d}$ (Fig. 10); 73 events have a duration of at least $3 \mathrm{~d}$, but only two of them last $13 \mathrm{~d}$. We therefore start with the discussion of the results for the heat waves with a duration up to $6 \mathrm{~d}$ and then elucidate the findings for the longer-lived heat waves. For the latter category, the results are likely less robust due to the small number of events. 


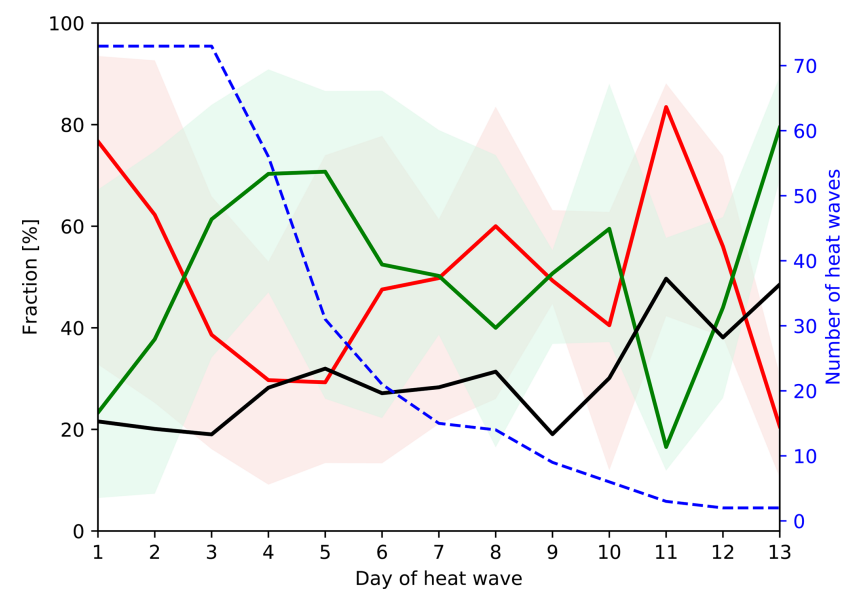

Figure 10. Latent heating during the life cycle of uppertropospheric anticyclones connected to heat waves in central Europe. The red (green) line shows the median contribution of the remote (nearby) heating branch to the whole heating branch, and the shading represents the range between the 25 th and 75 th percentile. The median fraction of the heating branch relative to all trajectories is represented by the black line, and the number of heat waves is indicated by the blue dashed line.

During the onset of a heat wave, the remote heating branch is of primary importance (Fig. 10). The formation of the upper-tropospheric anticyclone is therefore strongly affected by air masses that are diabatically heated in extratropical cyclones in the North Atlantic region. After the first $2 \mathrm{~d}$ of the heat waves, the nearby heating branch with air masses originating from northwestern Africa and heated diabatically due to convection below the western part of the ridge gains relevance (Fig. 10), thus supporting the maintenance of the upper-tropospheric anticyclone. The fraction of trajectories in the whole heating branch, i.e. remote and nearby heating branch together, with respect to all trajectories slightly increases during the maintenance of the upper-tropospheric anticyclone (black line in Fig. 10). Hence, the influence of latent heating increases during the life cycle of the events mainly due to an intensification of the nearby heating branch. At first sight, this result is contradictory to the findings of Pfahl et al. (2015) and Steinfeld and Pfahl (2019), who showed that the influence of latent heating reduces during the maintenance phase of atmospheric blocks. However, the heating relevant for atmospheric blocking mainly occurs in trajectories similar to our remote heating branch, and this branch loses relevance for the maintenance (up to day five) of upper-tropospheric anticyclones also here (Fig. 10).

Overall, the formation of upper-tropospheric anticyclones depends mainly on the latent heating within extratropical cyclones in the North Atlantic storm track, whereas the maintenance is related to air masses that are diabatically heated due to convection above western and central Europe. Although this pattern seems to be relevant for most of the heat waves, longer-lasting heat waves show a different behaviour.

The maintenance of heat waves beyond $6 \mathrm{~d}$ duration is more influenced by the remote heating branch compared to the maintenance of shorter lasting heat waves (Fig. 10). Note that these longer-lasting heat waves occur only rarely; therefore results are variable from case to case and less robust. However, it seems that the remote heating branch is revives and has a comparable influence as during the onset of the heat wave. We therefore hypothesise that long-lived uppertropospheric anticyclones cannot be sustained by the nearby heating branch alone. Rather, cyclones over the North Atlantic and the associated latent heat release are relevant to maintain the negative PV anomalies in the upper troposphere above the heat wave areas. In addition, the fraction of the heating branch related to all trajectories increases for longerlasting heat waves up to nearly $50 \%$.

\section{Conclusions}

In this study, we analysed the contribution of latent heating to the formation and maintenance of upper-tropospheric anticyclones associated with heat waves in different parts of Europe. Based on heat waves identified in Zschenderlein et al. (2019), we calculated backward trajectories from the anticyclones and separated the trajectories according to their potential temperature changes. The heating branch was further subdivided according to the location of the air parcels $3 \mathrm{~d}$ prior to the arrival in the upper-tropospheric anticyclone into a nearby and remote heating branch. Air parcels located west (east) of $30^{\circ} \mathrm{W} 3 \mathrm{~d}$ prior to the arrival belong to the remote (nearby) heating branch. In the Introduction, we raised specific research questions that we aim to summarise for central Europe with the help of Fig. 11.

1. What are typical source regions of low-PV air masses that constitute the upper-tropospheric anticyclones associated with European summer heat waves?

For central European heat wave anticyclones, mainly two geographic source regions exist; $3 \mathrm{~d}$ prior to reaching the upper-tropospheric anticyclones, air parcels in the cooling branch are located in the upper troposphere southwest of the target region, mainly distributed between central Europe and the central North Atlantic, peaking over the northwest coast of Africa (Fig. 11; label 1). Air parcels assigned to the nearby heating branch are located mainly between central Europe and the northwest coast of Africa in the mid-troposphere to lower troposphere (Fig. 11; label 3), while air parcels in the remote heating branch culminate between eastern North America and the western North Atlantic (Fig. 11; label 2) at similar altitudes. 
2. Are there inter-regional differences in the contribution of diabatic heating to the formation of these anticyclones?

Around $25 \%-45 \%$ (35\%-50\%) of the air parcels are diabatically heated during the last $3 \mathrm{~d}(7 \mathrm{~d})$ prior to the arrival in upper-tropospheric anticyclones. The influence of diabatic heating increases towards northern Europe and western Russia and decreases towards southern Europe. While most regions in Europe are - with varying magnitude - influenced by both the nearby and remote heating branch, western Russia is only influenced by one diabatic heating branch. The contribution of diabatic heating increases substantially on the $7 \mathrm{~d}$ timescale except for western Russia.

3. Where and in which synoptic environment does the diabatic heating occur in airflows entering the anticyclones?

For most regions in Europe, the diabatic heating occurs in two geographically separated moist ascending air streams. But the air streams differ not only in location; also the processes responsible for the diabatic heating are different. The remote heating branch is influenced by an enhanced activity of extratropical cyclones and associated warm conveyor belts over the North Atlantic. Diabatic heating in this branch is accompanied by stratiform precipitation, in contrast to the nearby heating branch, where convective-scale precipitation dominates. The moist ascent in the latter branch occurs closer to the target anticyclone in an environment of enhanced ML CAPE and is also aided by orographic lifting.

4. Are there differences in the relevance of diabatic heating during the formation and maintenance of the anticyclones?

The activity in the North Atlantic and the associated latent heat release in cyclones and warm conveyor belts are of primary importance for the onset of the uppertropospheric anticyclones connected to the heat waves. Their maintenance is affected by the more local diabatic heating in the nearby heating branch. For longer-lasting heat waves, the remote heating branch regenerates and becomes more relevant compared to days 3-5, implying that the ridge connected to the longer-lasting heat wave cannot be sustained without the transport of low-PV air to the upper troposphere within extratropical cyclones.

One shortcoming of our approach is that our trajectory calculations are not able to resolve small-scale convective processes. Hence, we possibly underestimate the effect of convection especially in the nearby heating branch and therefore the associated diabatic heating. Recently, Oertel et al. (2020) showed that embedded convection in warm conveyor belts can influence the synoptic-scale circulation and increase the isentropic PV gradient at upper levels in addition to the slant-

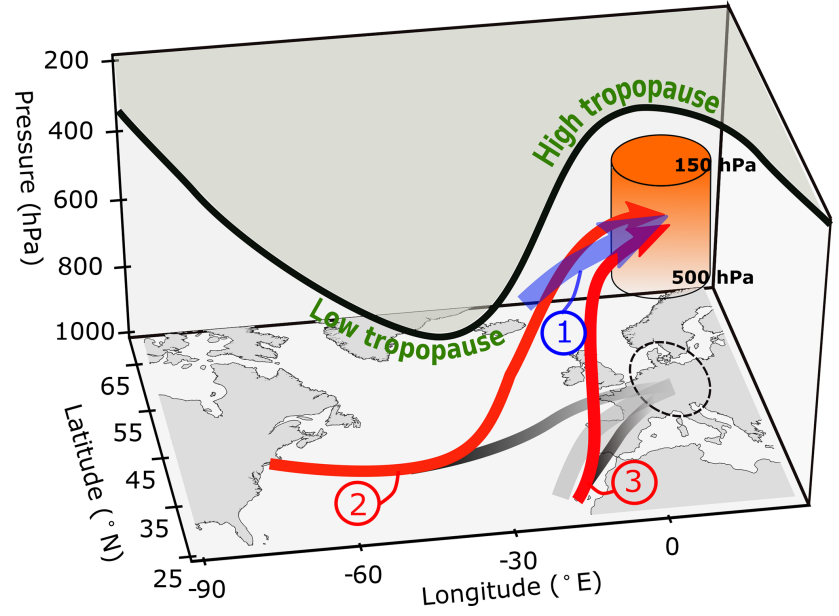

Figure 11. Schematic illustrating the pathway of the three air streams contributing to the upper-tropospheric anticyclone (red cylinder) above the heat wave in central Europe (black dashed circle) during the last $3 \mathrm{~d}$ prior to arrival. Air stream 1 denotes the cooling branch and air streams 2 and 3 the remote and nearby heating branches, respectively. Grey-marked lines at the surface illustrate the projections of the arrows (lighter grey indicates a higher altitude of the associated air stream). The bold black line represents the dynamical tropopause. The arrow of air stream 1 is wider because this branch is less spatially coherent compared to air streams 2 and 3.

wise WCB ascent. However, we assume that for our climatological analysis the source regions will not substantially change because also the convective ascending parcels are located in the vicinity of the slantwise-ascending WCB (Oertel et al., 2020) and we argue that convective parameterisation is tuned to capture the climatological bulk effects of deep convection on rainfall and latent heat release. For the nearby branch, especially in the Greece-Italy case, the pathway of individual trajectories affected by deep convection over the Atlas Mountains and the Alps might be more uncertain due to the proximity of convection to the heat wave region. Weisheimer et al. (2011) noted that a revised formulation of the convective parameterisations in the ECMWF model improved the predictability of the 2003 European heat wave. Interestingly, air parcels arriving over Greece-Italy can originate from the upper-level easterlies over western Africa (see Sect. 3.1). Pante and Knippertz (2019) show that explicit convection over western Africa improves forecast of upper-level fields over Europe at 5-8 d lead time. Thus, it would be interesting to calculate online, convection-permitting trajectories in high-resolution model simulations (e.g. Miltenberger et al., 2013) to study the impact of convection over the northern African subtropics and over southern Europe on the formation of European heat waves.

Our results have relevant implications for both weather and climate dynamics. The processes discussed in our study need to be correctly simulated in both state-of-the-art numerical weather prediction and climate models. Diabatic pro- 
cesses affect the life cycle of Rossby wave packets, and a misrepresentation of these processes can lead to reduced predictability (Rodwell et al., 2013). Grams et al. (2018) showed that a misrepresented warm conveyor belt in an upstream trough led to misforecasts in the onset of blocking situations over Europe. Also Rodwell et al. (2013) pointed out that convective situations in eastern North America led to a forecast bust over Europe. When considering a higher moisture content in the lower troposphere in a generally warmer world (Held and Soden, 2006), the latent heat release in cyclones or convective systems may increase. The stronger latent heat release stimulates the ascent of air streams that produce more significant negative PV anomalies in the upper troposphere (Madonna et al., 2014). Hence, model experiments quantifying the amplitude and the size of the upper-tropospheric anticyclones subject to a changing moisture content would be helpful in estimating the influence of global warming on the dynamics of European heat waves.

Data availability. ERA-Interim data can be downloaded from the ECMWF web page at https://apps.ecmwf.int/datasets/data/ interim-full-daily/levtype $=\mathrm{sfc}$ ( (last access: April 2020) (European Centre for Medium Range Weather Forecasts, 2020). Feature climatologies are available from Sprenger et al. (2017) and monthly mean feature frequencies directly from http://eraiclim.ethz.ch (last access: April 2020) (Atmospheric Dynamics Group, 2020). Vertically averaged PV fields are available upon request from the authors.

Supplement. The supplement related to this article is available online at: https://doi.org/10.5194/wcd-1-191-2020-supplement.

Author contributions. PZ carried out the analysis and SP; HW and AHF gave important guidance during the project. $\mathrm{PZ}$ wrote the paper, and all authors provided feedback on the paper.

Competing interests. The authors declare that they have no conflict of interest.

Acknowledgements. We thank ECMWF for providing access to ERA-Interim reanalysis data; Michael Sprenger and Lukas Papritz for providing access to the blocking, cyclone and warm conveyor belt datasets; Daniel Steinfeld for providing access to the vertically averaged PV dataset. We also thank Julian Quinting for inspiring discussions and both reviewers for their constructive comments.

Financial support. This research has been supported by the Deutsche Forschungsgemeinschaft (grant no. SFB/TRR 165, "Waves to Weather") and conducted within the subproject C4: "Coupling of planetary-scale Rossby wave trains to local extremes in heat waves over Europe".
Review statement. This paper was edited by Pedram Hassanzadeh and reviewed by Pak-Wah Chan and one anonymous referee.

\section{References}

Atmospheric Dynamics Group, Institute for Atmospheric and Climate Science at ETH Zurich, Feature-based ERA-Interim climatologies, available at: http://eraiclim.ethz.ch, last access: April 2020.

Browning, K. A., Hardman, M. E., Harrold, T. W., and Pardoe, C. W.: The structure of rainbands within a midlatitude depression, Q. J. Roy. Meteorol. Soc., 99, 215-231, https://doi.org/10.1002/qj.49709942002, 1973.

Brunner, L., Schaller, N., Anstey, J., Sillmann, J., and Steiner, A. K.: Dependence of present and future European temperature extremes on the location of atmospheric blocking, Geophys. Res. Lett., 45, 6311-6320, https://doi.org/10.1029/2018GL077837, 2018.

Carril, A. F., Gualdi, S., Cherchi, A., and Navarra, A.: Heatwaves in Europe: areas of homogeneous variability and links with the regional to large-scale atmospheric and SSTs anomalies, Clim. Dynam., 30, 77-98, https://doi.org/10.1007/s00382-007-0274-5, 2008.

Chan, P.-W., Hassanzadeh, P., and Kuang, Z.: Evaluating indices of blocking anticyclones in terms of their linear relations with surface hot extremes, Geophys. Res. Lett., 46, 4904-4912, https://doi.org/10.1029/2019GL083307, 2019.

Colucci, S. J.: Explosive Cyclogenesis and Large-Scale Circulation Changes: Implications for Atmospheric Blocking, J. Atmos. Sci., 42, 2701-2717, https://doi.org/10.1175/15200469(1985)042<2701:ECALSC>2.0.CO;2, 1985.

Croci-Maspoli, M., Schwierz, C., and Davies, H. C.: A Multifaceted Climatology of Atmospheric Blocking and Its Recent Linear Trend, J. Climate, 20, 633-649, https://doi.org/10.1175/JCLI4029.1, 2007.

Dee, D. P., Uppala, S. M., Simmons, A. J., Berrisford, P., Poli, P., Kobayashi, S., Andrae, U., Balmaseda, M. A., Balsamo, G., Bauer, P., Bechtold, P., Beljaars, A. C., van de Berg, L., Bidlot, J., Bormann, N., Delsol, C., Dragani, R., Fuentes, M., Geer, A. J., Haimberger, L., Healy, S. B., Hersbach, H., Hólm, E. V., Isaksen, L., Kållberg, P., Köhler, M., Matricardi, M., Mcnally, A. P., Monge-Sanz, B. M., Morcrette, J. J., Park, B. K., Peubey, C., de Rosnay, P., Tavolato, C., Thépaut, J. N., and Vitart, F.: The ERA-Interim reanalysis: Configuration and performance of the data assimilation system, Q. J. Roy. Meteorol. Soc., 137, 553597, https://doi.org/10.1002/qj.828, 2011.

Dong, B., Sutton, R. T., Woollings, T., and Hodges, K.: Variability of the North Atlantic summer storm track: mechanisms and impacts on European climate, Environ. Res. Lett., 8, 034037, https://doi.org/10.1088/1748-9326/8/3/034037, 2013.

European Centre for Medium Range Weather Forecasts: ERAInterim, available at: https://apps.ecmwf.int/datasets/data/ interim-full-daily/levtype=sfc/, last access: April 2020.

Fink, A. H., Engel, T., Ermert, V., van der Linden, R., Schneidewind, M., Redl, R., Afiesimama, E., Thiaw, W. M., Yorke, C., Evans, M., and Janicot, S.: Mean climate and seasonal cycle, Meteorology of Tropical West Africa: The Forecasters' Handbook, 
John Wiley \& Sons Ltd, Chichester, West Sussex, UK, 1-39, 2017.

Garcia-Herrera, R., Diaz, J., Trigo, R. M., Luterbacher, J., and Fischer, E. M.: A review of the European Summer Heat Wave of 2003, Crit. Rev. Environ. Sci. Technol., 40, 267-306, https://doi.org/10.1080/10643380802238137, 2010.

Grams, C. M., Wernli, H., Böttcher, M., Campa, J., Corsmeier, U., Jones, S. C., Keller, J. H., Lenz, C.-J., and Wiegand, L.: The key role of diabatic processes in modifying the upper-tropospheric wave guide: a North Atlantic case-study, Q. J. Roy. Meteorol. Soc., 137, 2174-2193, https://doi.org/10.1002/qj.891, 2011.

Grams, C. M., Magnusson, L., and Madonna, E.: An atmospheric dynamics perspective on the amplification and propagation of forecast error in numerical weather prediction models: A case study, Q. J. Roy. Meteorol. Soc., 144, 2577-2591, https://doi.org/10.1002/qj.3353, 2018.

Green, J. S. A., Ludlam, F. H., and McIlveen, J. F. R.: Isentropic relative-flow analysis and the parcel theory, Q. J. Roy. Meteorol. Soc., 92, 210-219, https://doi.org/10.1002/qj.49709239204, 1966.

Harrold, T. W.: Mechanisms influencing the distribution of precipitation within baroclinic disturbances, Q. J. Roy. Meteorol. Soc., 99, 232-251, https://doi.org/10.1002/qj.49709942003, 1973.

Held, I. M. and Soden, B. J.: Robust Responses of the Hydrological Cycle to Global Warming, J. Climate, 19, 5686-5699, https://doi.org/10.1175/JCLI3990.1, 2006.

Holton, J. R. and Hakim, G. J.: An Introduction fo Dynamic Meteorology, Elsevier Academic Press, Oxford, 2013.

Horton, D. E., Johnson, N. C., Singh, D., Swain, D. L., Rajaratnam, B., and Diffenbaugh, N. S.: Contribution of changes in atmospheric circulation patterns to extreme temperature trends, Nature, 522, 465-469, https://doi.org/10.1038/nature14550, 2015.

Horton, R. M., Mankin, J. S., Lesk, C., Coffel, E., and Raymond, C.: A Review of Recent Advances in Research on Extreme Heat Events, Curr. Clim. Change Rep., 2, 242-259, https://doi.org/10.1007/s40641-016-0042-x, 2016.

Lafore, J.-P., Flamant, C., Giraud, V., Guichard, F., Knippertz, P., Mahfouf, J.-F., Mascart, P., and Williams, E.: Introduction to the AMMA Special Issue on 'Advances in understanding atmospheric processes over West Africa through the AMMA field campaign', Q. J. Roy. Meteorol. Soc., 136, 2-7, https://doi.org/10.1002/qj.583, 2010.

Madonna, E., Wernli, H., Joos, H., and Martius, O.: Warm Conveyor Belts in the ERA-Interim Dataset (1979-2010). Part I: Climatology and Potential Vorticity Evolution, J. Climate, 27, 3-26, https://doi.org/10.1175/JCLI-D-12-00720.1, 2014.

Miltenberger, A. K., Pfahl, S., and Wernli, H.: An online trajectory module (version 1.0) for the nonhydrostatic numerical weather prediction model COSMO, Geosci. Model Dev., 6, 1989-2004, https://doi.org/10.5194/gmd-6-1989-2013, 2013.

Oertel, A., Boettcher, M., Joos, H., Sprenger, M., and Wernli, H.: Potential vorticity structure of embedded convection in a warm conveyor belt and its relevance for large-scale dynamics, Weather Clim. Dynam., 1, 127-153, https://doi.org/10.5194/wcd-1-1272020, 2020.

Pante, G. and Knippertz, P.: Resolving Sahelian thunderstorms improves mid-latitude weather forecasts, Nat. Commun., 10, 1-9, https://doi.org/10.1038/s41467-019-11081-4, 2019.
Perkins, S. E., Alexander, L. V., and Nairn, J. R.: Increasing frequency, intensity and duration of observed global heatwaves and warm spells, Geophys. Res. Lett., 39, L20714, https://doi.org/10.1029/2012GL053361, 2012.

Pfahl, S.: Characterising the relationship between weather extremes in Europe and synoptic circulation features, Nat. Hazards Earth. Syst. Sci., 14, 1461-1475, https://doi.org/10.5194/nhess14-1461-2014, 2014.

Pfahl, S. and Wernli, H.: Quantifying the relevance of atmospheric blocking for co-located temperature extremes in the Northern Hemisphere on (sub-)daily time scales, Geophys. Res. Lett., 39, L12807, https://doi.org/10.1029/2012GL052261, 2012.

Pfahl, S., Schwierz, C., Croci-Maspoli, M., Grams, C. M., and Wernli, H.: Importance of latent heat release in ascending air streams for atmospheric blocking, Nat. Geosci., 8, 610-614, https://doi.org/10.1038/ngeo2487, 2015.

Pomroy, H. R. and Thorpe, A. J.: The Evolution and Dynamical Role of Reduced Upper-Tropospheric Potential Vorticity in Intensive Observing Period One of FASTEX, Mon. Weather Rev., 128, 1817-1834, https://doi.org/10.1175/15200493(2000)128<1817:TEADRO>2.0.CO;2, 2000.

Quinting, J. F. and Reeder, M. J.: Southeastern Australian Heat Waves from a Trajectory Viewpoint, Mon. Weather Rev., 145, 4109-4125, https://doi.org/10.1175/MWR-D-17-0165.1, 2017.

Rodwell, M. J., Magnusson, L., Bauer, P., Bechtold, P., Bonavita, M., Cardinali, C., Diamantakis, M., Earnshaw, P., GarciaMendez, A., Isaksen, L., Källén, E., Klocke, D., Lopez, P., McNally, T., Persson, A., Prates, F., and Wedi, N.: Characteristics of Occasional Poor Medium-Range Weather Forecasts for Europe, B. Am. Meteorol. Soc., 94, 1393-1405, https://doi.org/10.1175/BAMS-D-12-00099.1, 2013.

Röthlisberger, M., Pfahl, S., and Martius, O.: Regional-scale jet waviness modulates the occurrence of midlatitude weather extremes, Geophys. Res. Lett., 43, 10989-10997, https://doi.org/10.1002/2016GL070944, 2016.

Schwierz, C., Croci-Maspoli, M., and Davies, H. C.: Perspicacious indicators of atmospheric blocking, Geophys. Res. Lett., 31, L06125, https://doi.org/10.1029/2003GL019341, 2004.

Sousa, P. M., Trigo, R. M., Barriopedro, D., Soares, P. M. M., and Santos, J. A.: European temperature responses to blocking and ridge regional patterns, Clim. Dynam., 50, 457-477, https://doi.org/10.1007/s00382-017-3620-2, 2018.

Sprenger, M. and Wernli, H.: The LAGRANTO Lagrangian analysis tool - version 2.0, Geosci. Model Dev., 8, 2569-2586, https://doi.org/10.5194/gmd-8-2569-2015, 2015.

Sprenger, M., Fragkoulidis, G., Binder, H., Croci-Maspoli, M., Graf, P., Grams, C. M., Knippertz, P., Madonna, E., Schemm, S., Škerlak, B., and Wernli, H.: Global Climatologies of Eulerian and Lagrangian Flow Features based on ERA-Interim, B. Am. Meteorol. Soc., 98, 1739-1748, https://doi.org/10.1175/BAMSD-15-00299.1, 2017.

Stefanon, M., D'Andrea, F., and Drobinski, P.: Heatwave classification over Europe and the Mediterranean region, Environ. Res. Lett., 7, 014023, https://doi.org/10.1088/1748-9326/7/1/014023, 2012.

Steinfeld, D. and Pfahl, S.: The role of latent heating in atmospheric blocking dynamics: a global climatology, Clim. Dynam., 53 , 6159-6180, https://doi.org/10.1007/s00382-019-04919-6, 2019. 
Tomczyk, A. M. and Bednorz, E.: Heat waves in Central Europe and tropospheric anomalies of temperature and geopotential heights, Int. J. Climatol., 39, 4189-4205, https://doi.org/10.1002/joc.6067, 2019.

Watts, N., Amann, M., Ayeb-Karlsson, S., Belesova, K., Bouley, T., Boykoff, M., Byass, P., Cai, W., Campbell-Lendrum, D., Chambers, J., Cox, P. M., Daly, M., Dasandi, N., Davies, M., Depledge, M., Depoux, A., Dominguez-Salas, P., Drummond, P., Ekins, P., Flahault, A., Frumkin, H., Georgeson, L., Ghanei, M., Grace, D., Graham, H., Grojsman, R., Haines, A., Hamilton, I., Hartinger, S., Johnson, A., Kelman, I., Kiesewetter, G., Kniveton, D., Liang, L., Lott, M., Lowe, R., Mace, G., Odhiambo Sewe, M., Maslin, M., Mikhaylov, S., Milner, J., Latifi, A. M., MoradiLakeh, M., Morrissey, K., Murray, K., Neville, T., Nilsson, M., Oreszczyn, T., Owfi, F., Pencheon, D., Pye, S., Rabbaniha, M., Robinson, E., Rocklöv, J., Schütte, S., Shumake-Guillemot, J., Steinbach, R., Tabatabaei, M., Wheeler, N., Wilkinson, P., Gong, P., Montgomery, H., and Costello, A.: The Lancet Countdown on health and climate change: from 25 years of inaction to a global transformation for public health, Lancet, 391, 581-630, https://doi.org/10.1016/s0140-6736(17)32464-9, 2018.
Weisheimer, A., Doblas-Reyes, F. J., Jung, T., and Palmer, T. N.: On the predictability of the extreme summer 2003 over Europe, Geophys. Res. Lett., 38, L05704, https://doi.org/10.1029/2010GL046455, 2011.

Wernli, H. and Schwierz, C.: Surface Cyclones in the ERA40 Dataset (1958-2001). Part I: Novel Identification Method and Global Climatology, J. Atmos. Sci., 63, 2486-2507, https://doi.org/10.1175/JAS3766.1, 2006.

Yamazaki, A. and Itoh, H.: Vortex-Vortex Interactions for the Maintenance of Blocking. Part I: The Selective Absorption Mechanism and a Case Study, J. Atmos. Sci., 70, 725-742, https://doi.org/10.1175/JAS-D-11-0295.1, 2013.

Zschenderlein, P., Fink, A. H., Pfahl, S., and Wernli, H.: Processes determining heat waves across different European climates, Q. J. Roy. Meteorol. Soc., 145, 2973-2989, https://doi.org/10.1002/qj.3599, 2019. 